\title{
Scaled Model Tests on the Influence of Reinforcement Spacing on the Deformation of Reinforced Retaining Wall
}

\author{
Di WU \\ College of Architecture and Transportation Engineering \\ Guilin University of Electronic Technology \\ Guilin, China \\ E-mail: adi823@163.com
}

\author{
Jianjian WU \\ College of Architecture and Transportation Engineering \\ Guilin University of Electronic Technology \\ Guilin, China \\ E-mail: 18172678956@189.cn
}

\author{
Qian LI \\ College of Architecture and Transportation Engineering \\ Guilin University of Electronic Technology \\ Guilin, China \\ E-mail: m13998438015_1@163.com
}

\begin{abstract}
Reinforced earth retaining wall is a kind of retaining wall which can bear lateral pressure of soil, which is made up of fill, stressed geosynthetics and retaining blocks. It can enhance the strength and stability of soil with the interaction between the reinforced material and the soil by arranging the tensile material, especially geogrid, in the tensile deformation region of the soil. In the researches on reinforced soil retaining wall, scaled model tests are more effective than any other methods Domestic and foreign scholars have done some valuable researches, but the reinforcement spacing effects of the retaining wall were still not fully resolved currently in academic sector. In this paper, different reinforcement spacing walls were made and monitored, and some research analysis have been done on the deformation characteristics of reinforced retaining wall with different reinforcement spacing. The results show that the settlement on the top as well as the lateral displacement on the front surface of the reinforced retaining wall increased with the increase of the reinforcement spacing.
\end{abstract}

Keywords-reinforced retaining wall; scaled model tests; reinforcement spacing; vertical settlement; lateral displacement; geogrid

\section{INTRODUCTION}

Geosynthetics is widely used as reinforcement material in the engineering practice of modern reinforced soil structure, because of the low cost, light weight and convenient construction[1-3]. The role of geosynthetics in the reinforcement is that geosynthetics and soil together constitute a complex, so both strength and the deformation properties of the complex can be improved than before. There have been reinforced retaining walls, reinforced soil steep slopes, reinforced soil foundations, pile-supported and geosynthetic-reinforced embankments as well as other reinforced soil structure in the existing engineering practice, which all have unique advantages.

However, the existing failure mode and the precise constitutive relation of the reinforced soil were not fully understood, and the influence of the reinforcement is not clear because of the complexity[4-6]. The actual performance and state of the reinforced earth retaining wall still need to be further studied by model tests or numerical simulations; because the calculations and design methods of reinforced soil structure adopted many assumptions which could be not accurate or even wrong for all. The scaled model tests of reinforced soil retaining wall were carried out to focus on the influence of different geogrid reinforced spacing on the deformation of reinforced retaining wall which has a relatively larger deformation than any other retaining walls. The multi-point displacement monitoring of the scaled retaining wall models was carried out to study the influence of reinforcement spacing on the performance and state of the reinforced retaining wall by changing the load on top of the retaining wall and number of geogrid layers inside the retaining wall.

\section{SCAlED Model TeStS}

The experiment consisted of three sets of models. The size of the scale model was $120 \mathrm{~cm} \times 60 \mathrm{~cm} \times 100 \mathrm{~cm}$ (length $x$ width $\times$ height). The relevant information of each model is shown in Tab. 1 .

TABLE I. INFORMATION OF SCALED MODEL TESTS

\begin{tabular}{cccc}
\hline Test & $\begin{array}{c}\text { Reinforcement } \\
\text { Spacing }\end{array}$ & $\begin{array}{c}\text { Number of } \\
\text { Dial Gauges }\end{array}$ & $\begin{array}{c}\text { Number of Geogrid } \\
\text { Layers }\end{array}$ \\
\hline M1 & $20 \mathrm{~cm}$ & 7 & 5 \\
M2 & $30 \mathrm{~cm}$ & 7 & 3 \\
M3 & $40 \mathrm{~cm}$ & 7 & 3 \\
\hline
\end{tabular}

The side wall panel is arranged by vertically placing a model box with one side opening which is made of wood panels. There are three rows of holes arranged regularly on both sides of the panel in a stiffened dimension. The bar linked to the screw steel bars arranged holes together. And the wire link up with geogrid. Test equipment used in the selection of 50kN hydraulic jack, which is loaded manually. Schematic diagram and field model test of the scaled model tests are shown in Fig. 1. 
In this experiment, glass fiber geogrid was used as the reinforcement material. The length of each layer of reinforcement designed to take $90 \mathrm{~cm}$ for security. The glass fiber geogrid is chosen as the research reinforcement material; because the strength of glass fiber geogrid is lower than other grids, it meets the needs of scaled model tests. Experiments were performed with quartz sand. From 4 to 6 meshes, 20 to 40 meshes and 30 to 60 mesh quartz sand were mixed according to the mass ratio of $1: 1: 1$, and stirred well. The stratified compaction method is adopted in the experiments, and the density of the controlled quartz sand is about $2.3 \mathrm{~g} / \mathrm{cm}^{3}$. Particle analysis was performed on quartz sand, and the parameters obtained are shown in Tab. 2.

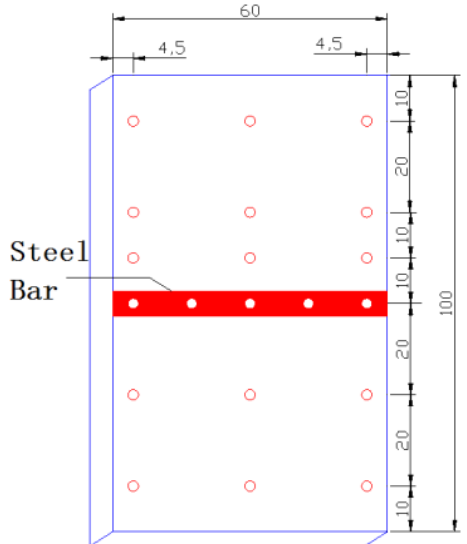

(a)

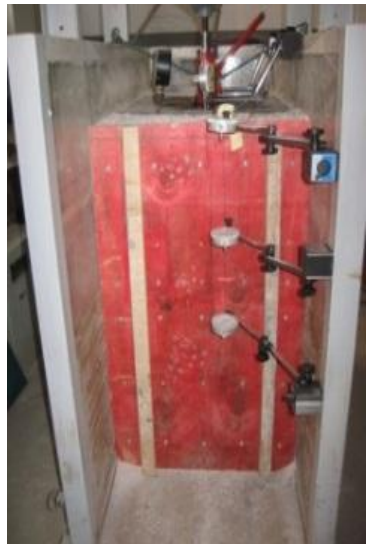

(b)
Figure 1. Scaled model tests in this study: (a) schematic diagram of front view; (b) field model test of front view

TABLE II. BASIC PARAMETERS OF QUARTZ SAND

\begin{tabular}{ccccc}
\hline $\begin{array}{c}\text { Limiting } \\
\text { Particle } \\
\text { Size }\end{array}$ & $\mathbf{d}_{\mathbf{3}}$ & $\mathbf{d}_{\mathbf{1 0}}$ & $\begin{array}{c}\text { Non-uniformity } \\
\text { Coefficient }\end{array}$ & $\begin{array}{c}\text { Curvature } \\
\text { Coefficient }\end{array}$ \\
\hline $2.2 \mathrm{~mm}$ & $0.76 \mathrm{~mm}$ & $0.56 \mathrm{~mm}$ & 3.93 & 0.47 \\
\hline
\end{tabular}

The arrangement of displacement monitoring elements of the model tests is shown in Fig. 2.

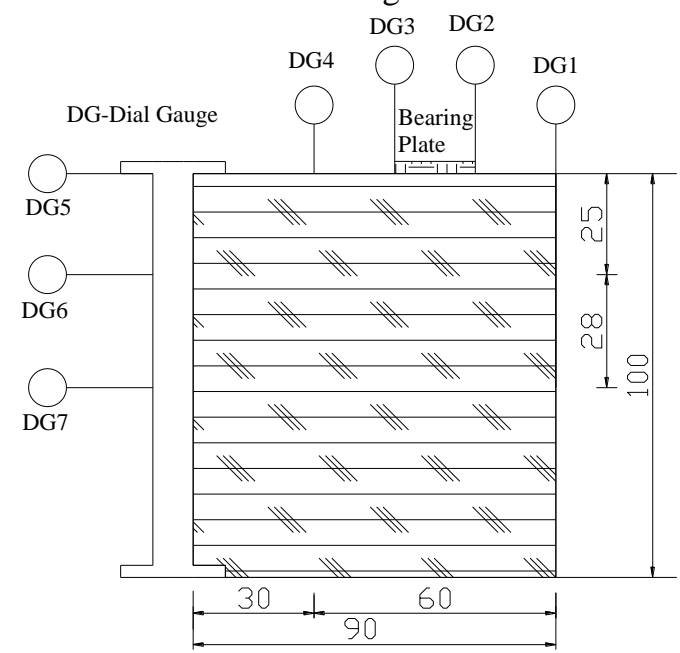

Figure 2. Section of reinforced retaining wall and dial gauges (unit: $\mathrm{cm}$ )
The main test process is as follows:

(1) Preparation. Layer marks are drew well on the model box, and dial gauges are calibrated.

(2) Quartz sand is filled and fiber glass geogrid is laid according to the design layout of the model structure

(3) After the model is built, 2-3 days are delayed to make the model deformation stable.

Step-by-step loading is used in the scaled model tests. The model is loaded $5 \mathrm{kN}$ per hour, and the maximum loaded is $30 \mathrm{kN}$. After the last load is completed, a whole night is delayed to make the model stable. The vertical displacement on the top and the horizontal displacement on the side wall of the retaining wall models are monitored. The monitored data of $1 \mathrm{~min}, 2 \mathrm{~min}, 5 \mathrm{~min}, 10 \mathrm{~min}, 20 \mathrm{~min}$, $30 \mathrm{~min}$, and 60min are read according to load before loading and after loading. Each level of loading is repeated once during the entire loading process.

\section{TEST RESULTS AND ANALYSIS}

The seven displacement dial gauges were located on the top and front side wall panel of retaining wall models. The displacement of the retaining wall was monitored. Four dial gauges were arranged on the top of the retaining wall, and the three dial gauges were uniformly arranged on the front side panel of the retaining wall. Part of the layout of the dial gauges was shown in Fig. 2.

Each set of model walls was loaded with 6 levels throughout the testing process. Each level of loading was 1 hour continuance. In this study, the data monitored on the top and on the front surface of the retaining walls were focused on. The data would indicate the influence of reinforcement spacing on deformation of reinforced retaining wall.

Fig. 3 to Fig. 6 (DG1 to DG4) shows the displacement curves on the horizontal plane of the retaining wall top during the whole loading process. Different reinforcement spacing $(20 \mathrm{~cm}, 30 \mathrm{~cm}$ and $40 \mathrm{~cm}$ spacing) was arranged inside of reinforced retaining wall models.

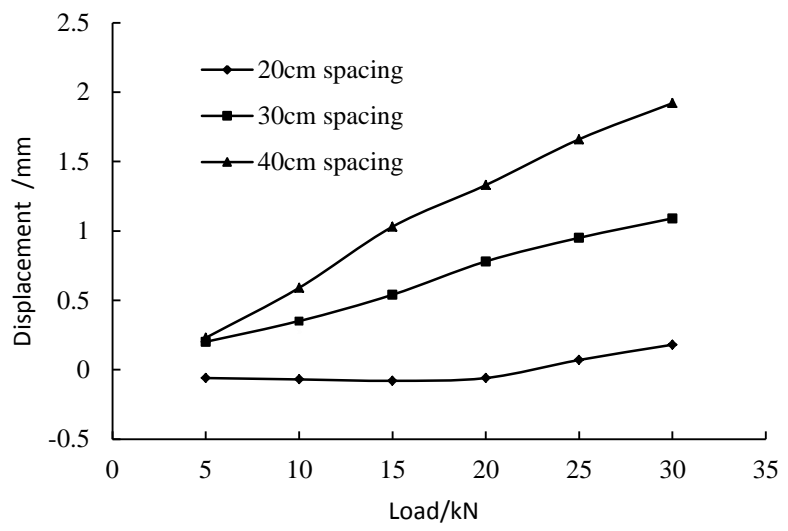

Figure 3. Curves of displacement measured by DG1 


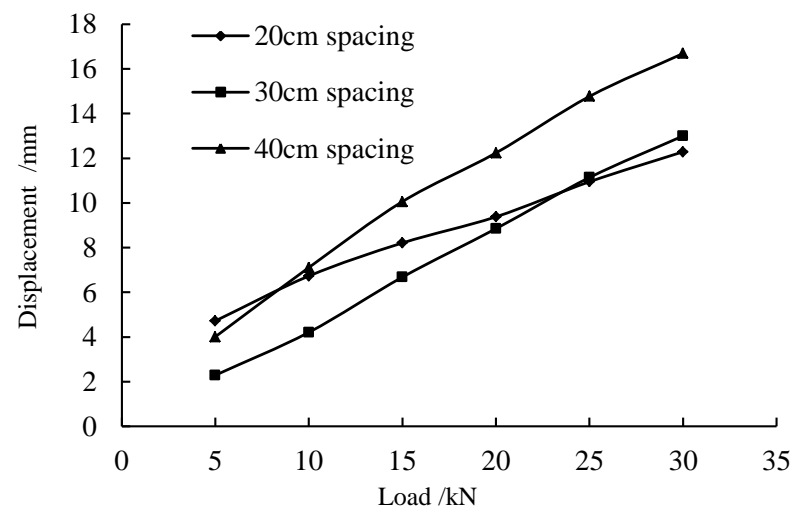

Figure 4. Curves of displacement measured by DG2

When the reinforcement spacing of the retaining wall model was $40 \mathrm{~cm}(\mathrm{M} 3)$, the displacement and increment of displacement were the biggest under each load level. When the reinforcement spacing of the retaining wall model was $20 \mathrm{~cm}$ (M1), the increment of displacement was the smallest under each load level.

DG2 and DG3 were located on the bearing plate, and their displacement curves of M1 and M2 intersected with each other at $20 \mathrm{kN}$ to $25 \mathrm{kN}$ load level. For DG 1 and DG 4 , the displacement curves of M1 and M2 did not intersect with each other. This difference indicated a higher degree of compaction under the bearing plate. While at the same time, the two dial gauges had still looser sand outside the bearing plate.

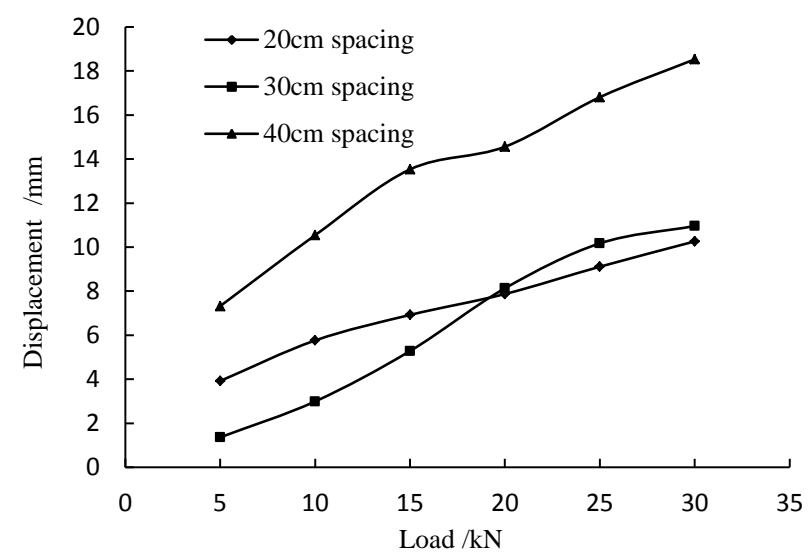

Figure 5. Curves of displacement measured by DG3

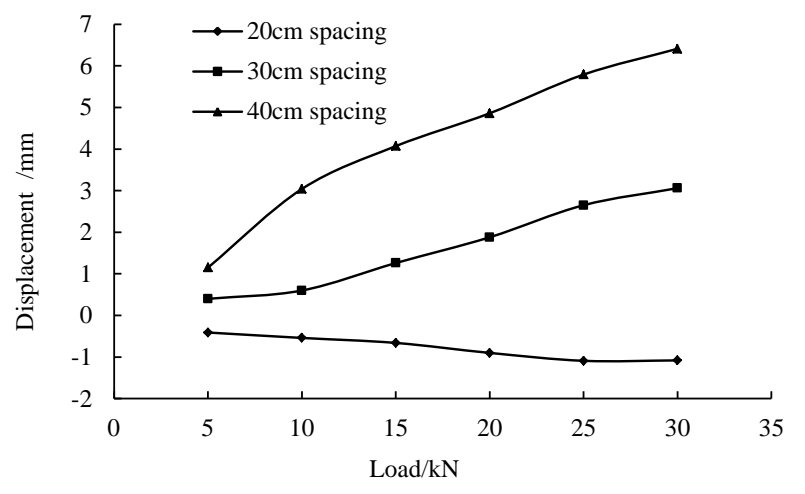

Figure 6. Curves of displacement measured by DG4

It can clearly be seen from Figure 7 that the measured vertical displacement of DG 2 and DG 3 on the bearing plate is the largest when the reinforcement spacing was $40 \mathrm{~cm}$ (M3); and the total displacement of DG 3 and DG 2 was $18.527 \mathrm{~mm}$ and $16.724 \mathrm{~mm}$, respectively. Similarly, when the reinforcement spacing is $30 \mathrm{~cm}$ (M2) and $20 \mathrm{~cm}$ (M3), the total displacement of different dial indicators can also be clearly seen from the figure, which were obviously higher than DG1 and DG4. This is because DG2 and DG3 were located on the bearing plate which had a larger displacement due to loading.

When the reinforcement spacing was $40 \mathrm{~cm}$ (M3), the total displacement of DG 1 and DG 4 was $1.928 \mathrm{~mm}$ and $6.426 \mathrm{~mm}$, respectively. M1 and M2 also had a relatively smaller displacement. DG1 and DG4 were located relatively far from bearing plate, so the displacements were slightly smaller in magnitude.

It should be noted that the total displacement appeared negative when the reinforcement spacing was M1 of DG4 in figure 7. The reason for this phenomenon was DG4 (Located next to the pressure plate) occurred an excessive displacement, and it caused bulging effect, so that the displacement of DG 4 was negative.

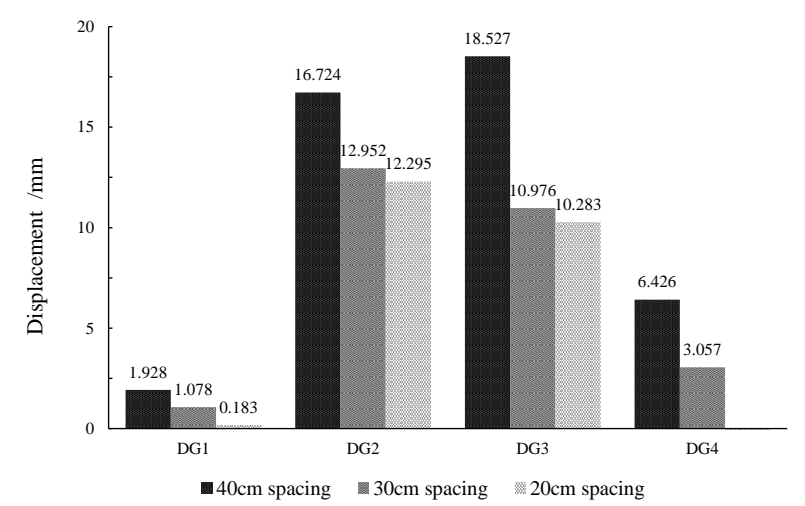

Figure 7. Comparison of displacements by the same dial gauge on the top of the retaining walls

Fig. 8 to Fig. 10 (DG5 to DG7) shows the displacement curves of 3 dial gauges on the front surface panel. These three figures indicate that the displacement increased with 
the increase of the load, and the displacement increment of the retaining wall model was the largest when the reinforcement spacing is $40 \mathrm{~cm}$ (M3). The M2 displacement increments of the retaining wall model were smaller than M3, and the displacement increments of M1 were the smallest.

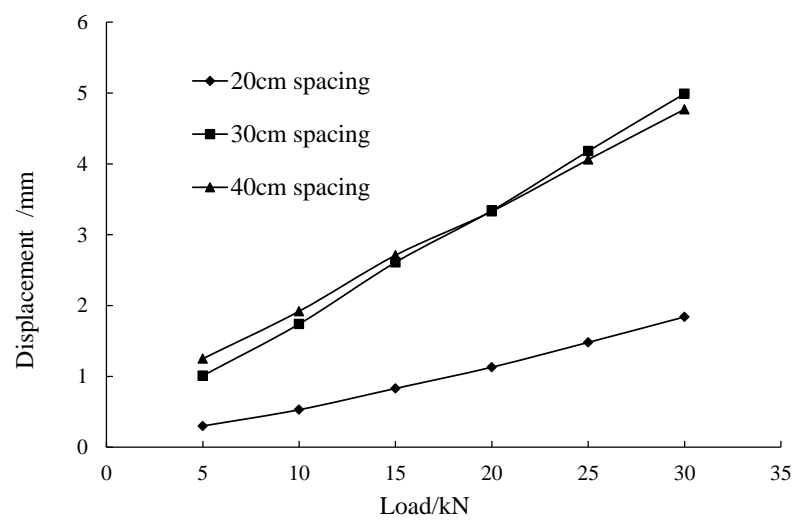

Figure 8. Curves of displacement measured by DG5

For the displacement increment, the retaining wall models with $40 \mathrm{~cm}$ and $30 \mathrm{~cm}$ reinforcement spacing were in close proximity. While the incremental displacement of retaining wall model with $20 \mathrm{~cm}$ reinforcement spacing was the smallest. In the model design, the design of the length of the reinforcement and the external loads was safe. So the lateral extrusion of the reinforcement was small under the external load. In other words, the displacement on the retaining wall panel was small.

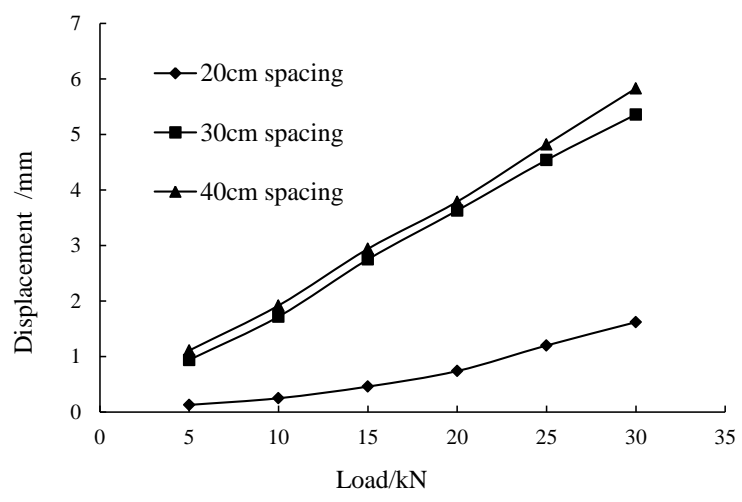

Figure 9. Curves of displacement measured by DG6

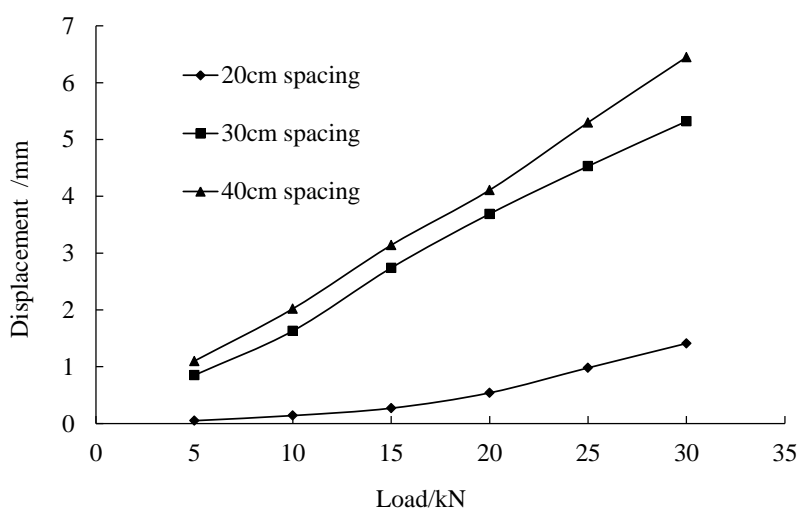

Figure 10. Curves of displacement measured by DG7

As can be seen from Figure 11, when the reinforcement spacing was $40 \mathrm{~cm}(\mathrm{M} 3)$, the total displacement value of DG 7 showed the maximum.

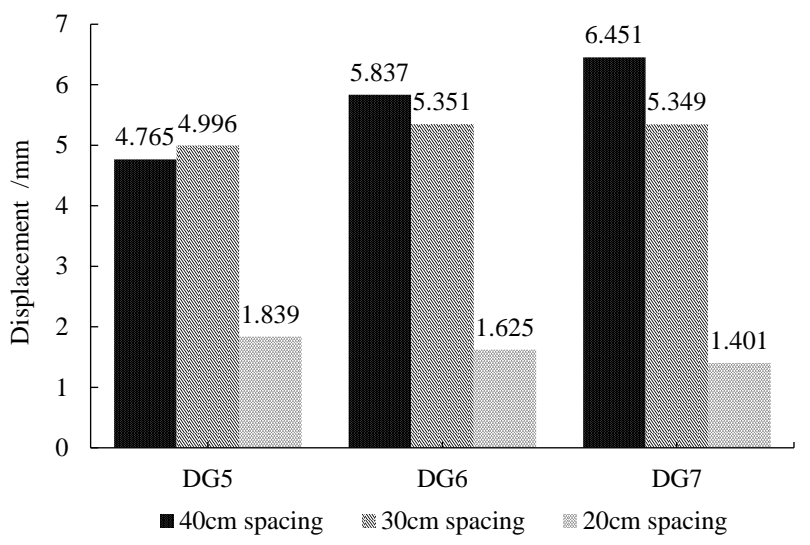

Figure 11. Comparison of displacements by the same dial gauge on the front surface of the retaining walls

When the reinforcement spacing of the model wall was $40 \mathrm{~cm}$ (M3), the displacement value of DG5 was smallest, while the total displacement value of DG6 showed the maximum. When the reinforcement spacing was $20 \mathrm{~cm}$ (M1), the displacement value of DG7 was in the middle, and the displacement value of DG5 was the smallest, while the total displacement value of DG 5 showed the maximum. Because the reinforcement spacing was not the same, the geogrid arrangement position was different. The positions of the displacement dial gauges were fixed, so the trends of the different measurements were different.

\section{CONCLUSIONS}

In this paper, reinforced retaining walls with different reinforcement spacing were studied by scaled model tests. The measured data of dial gauges on the top as well as on the front surface of the retaining walls were obtained. This paper also analyzed the data obtained from experimental monitoring to investigate the influence of reinforcement spacing on the deformation of reinforced retaining walls. The following conclusions were obtained: 
(1) In the same reinforcement spacing condition, the measured deformation of geogrid reinforced retaining wall was increased as the load of bearing plate increased.

(2) The settlement on the top as well as the lateral displacement on the front surface of the reinforced retaining wall increased with the increase of the reinforcement spacing.

\section{ACKNOWLEDGMENT}

Financial support for this work is gratefully acknowledged from the Natural Science Foundation of Guangxi Grant 2015GXNSFBA139236 and Guangxi University Scientific Research Project Grant KY2015ZD044. All the support is greatly appreciated.

\section{REFERENCES}

[1] Hoe I. Ling, M.ASCE; Huabei Liu; ect. Analyzing dynamic behavior of geosynthetic-reinforced soil retaining walls, Journal of engineering mechanics, Vol.2004, 8:911-920.

[2] Huei-Tsyr Chen, Wen-Yi Hung, Chin-Chang Chang, Yuan-Ji Chen, Chung-Jung Lee. Centrifuge modeling test of a geotextile-reinforced wall with a very wet clayey backfill,Geotextiles and Geomembranes, Vol.2007,25(2):346-359.

[3] Ehrlich M, Becker L.D.B, Reinforced soil wall measurements and predictions, 9th International Conference on Geosynthetics, Brazil, Vol. 2010: 547-560.

[4] Patrick Wilson, Ahmed Elgamal. Large-Scale Passive Earth Pressure Load-Displacement Tests and Numerical Simulation . Journal of geotechnical and geoenvironmental engineering. Vol. 2010, 136(12), 1634-1643.

[5] Latha, G.M., Krishna, A.M., Seismic response of reinforced soil retaining wall models: influence of backfill relative density. Geotextiles and Geomembranes,Vol. 2008. 26 (4), 335-349.

[6] El-Emam, M.M., Bathurst, R.J. Influence of reinforcement parameters on the seismic response of reduced-scale reinforced soil retaining walls. Geotextiles and Geomembranes, Vol. 2007. 25(1), $33-49$. 